\title{
A RestauRAçÃo do OdEION de PÉRICLES EM ATENAS NO SÉCULO I A.C.: NOVOS E ANTIGOS PERSAS
}

Fábio Augusto Morales ${ }^{1}$

\begin{abstract}
Resumo
$\mathrm{O}$ artigo discute a restauração do Odeion de Péricles em Atenas, realizada por rei Ariobarzanes II da Capadócia entre 63 e 51 a. C. O teatro coberto, localizado próximo à encosta sudeste da acrópole, foi construído no século $\mathrm{V}$ a. $\mathrm{C}$. e destruído durante o cerco do general romano Sula à cidade em 86 a. C., seja pelos invasores, seja pelos sitiados. A restauração deste "monumento anti-persa" é extremamente significativa para a compreensão das políticas externas ateniense na primeira metade do século I a. C., quando o poder romano criou um novo quadro geopolítico no Mediterrâneo oriental; argumenta-se que a formação de uma identidade anti-bárbara, profundamente relacionada a uma propaganda que relacionava Mitrídates e os partas aos antigos persas, foi a principal motivação para a intervenção capadócia no espaço urbano ateniense. A partir do ponto de vista da história urbana ateniense, a restauração é um exemplo eloquente de uma nova atitude diante do espaço urbano, que se tornaria uma característica central nas intervenções urbanas de Atenas nos período tardo-republicano e augustano: o urbanismo antiquário.
\end{abstract}

\section{Palavras-Chaves}

Odeion de Péricles; Ariobarzanes; Capadócia; Sula; Atenas romana; ervergetismo helenístico.

\footnotetext{
${ }^{1}$ Professor Doutor. Pontifícia Universidade Católica de Campinas - Campinas, SP, Brasil. e-mail: fabiomorales@usp.br
} 


\begin{abstract}
This paper discusses the restoration project of the Odeion of Perikles at Athens, carried by the Cappadocian king Ariobarzanes II sometime between 63 and 52 BC, after its partial destruction during the Sullan sack of $86 \mathrm{BC}$. This sack occurred as a punishment for the alliance between Athens and the Pontic king Mithridates VI in his war against Rome. In that context, the restoration project of this fifth century B.C. covered-theatre was meaningful for the formation of diplomatic links and networks between Athens, Rome and Cappadocia, in particular considering the complexity of the antibarbarian narratives involved. From the viewpoint of the Athenian urban history, the restoration project is an eloquent example of a new attitude towards the urban space which would become a central feature in the social production of Athenian space throughout the first century B.C.: the antiquarian urbanism.
\end{abstract}

\title{
Keywords
}

Odeion of Perikles; Ariobarzanes II of Cappadocia; Sula; Roman Athens; Hellenistic Euergetism. 
Dificilmente outra cidade grega, além de Atenas, conseguiria concentrar em seus monumentos e em sua cultura literária tantos testemunhos da oposição dos gregos aos persas: dos frisos dos templos aos enredos trágicos, dos discursos retóricos aos espólios abrigados em santuários, a participação ateniense na vitória grega tornou-se um elemento central da identidade cívica local do período clássico em diante (Hall, 1989; Miller, 1997; Hall, 2002). A proliferação de imagens de gigantes, centauros, amazonas, troianos e persas nos espaços sagrados da cidade, ironicamente, inseririam de modo indelével os "bárbaros" na cidade que a tanto custo os repeliu. Este artigo visa discutir um caso específico desta ambígua inclusão de bárbaros na paisagem urbana ateniense, a saber, a restauração do Odeion de Péricles nos séculos I a.C., um edifício profundamente relacionado ao discurso anti-bárbaro ateniense. As múltiplas dimensões e significados desta restauração serão discutidos nos termos tanto dos processos de integração no Mediterrâneo (Horden e Purcell, 2000; Morris, 2003; Guarinello, 2003 e 2010) quanto da história da produção evergética do espaço urbano ateniense (Morales, 2015).

Em um livro recente, Kostas Vlassopoulos (2013) criticou a ênfase historiográfica nas relações conflituosas entre gregos e bárbaros, especialmente após as Guerras Médicas. De acordo com o autor,

\section{[...] many scholars agree that the distinction between Greeks and Barbarians had little importance during archaic period; it was only in the early classical period that Greeks created a categorical distinction between themselves and the Barbarians, and constructed a discourse of identity that exalted Greek identity and Greek culture, and viewed the Barbarians in a dismissive and pejorative manner that sometimes bordered on being racist. [...] There is undoubtedly an element of truth in the above description, but it is also deeply misleading. This description presupposes that each period had a single way of constructing Greek identity and its relationships to the Barbarians. But this is hardly credible given the peculiar nature of the Greek world (Vlassopoulos, 2013: 35-34).}

$\mathrm{O}$ autor prossegue discutindo as peculiaridades do mundo grego - a "perene falta de unidade ou de um centro, e a grande diversidade entre comunidades gregas (Vlassopoulos, 2013: 36) - e os múltiplos modos pelos quais os gregos se relacionaram aos "quatro mundos paralelos" dos impérios, do panhelenismo, das redes e das coloniais, os quais modelaram tanto a cultura grega quanto as culturas de comunidades influenciadas pelos gregos ao longo do Mediterrâneo na longa duração (Vlassopoulos: 013: 34-128). Entretanto, o discurso antibárbaro, mesmo que frequentemente tomado como exemplo maior pela historiografia do período clássico e pós-clássico centrada nas relações conflituosas, foi não obstante um importante canal de comunicação entre gregos e não gregos, justamente porque a definição da identidade bárbara não era um monopólio das comunidades gregas (Champion, 2004: 30-66). Embora exaustivamente estudado no caso dos usos romanos de identidades 
bárbaras (Spawforth, 2012: 103-106, com bibliografia anterior), este fenômeno recebeu pouca atenção para períodos tais como a época helenística, quando, após o estabelecimento de monarquias gregas ao longo do Mediterrâneo e no Oriente Próximo, asserções de identidade grega tornaram-se um importante mecanismo para a legitimação do poder (Gruen, 2006; Burstein, 2008; Vlassopoulos, 2013: 278-320). Neste contexto, paisagens urbanas gregas eram particularmente adequadas para tal operação (Veyne, 1976: 233; Ma, 2013: 67-110), e Atenas, com seus vários monumentos antibárbaros - tais como o Odeion de Péricles - era certamente um palco privilegiado.

O edifício conhecido como "Odeion de Péricles" (figs. 1 e 2) era um teatro coberto situado na encosta sudeste da acrópole, junto ao teatro de Dioniso. Este odeion - um dos três existentes na cidade ${ }^{2}$ - é conhecido a partir de escassas referências literárias e epigráficas ${ }^{3}$, às quais se somaram as conclusões derivadas de escavações parciais realizadas em diferentes momentos do século $X X^{4}$. Trata-se de um edifício hipostilo de planta aproximadamente quadrangular (c. 62x68m), coberto por um teto piramidal suportado por 90 colunas (9 fileiras no sentido leste-oeste e 10 no sentido norte-sul) com espaço interaxial regular de 6,15m. Não é claro se o edifício tinha paredes, e, caso positivo, onde estaria sua entrada principal. M. Korres (apud Miller, 1997: 229-230) sugere mesmo que o edifício não tinha muros, o que resolveria problemas de iluminação e ventilação; o controle do acesso de daria seja com uso de estruturas provisórias, seja pelas restrições impostas pela alta plataforma sobre a qual o edifício estava assentado. O número e disposição de tantas colunas eram, não obstante, um problema para a visualização das atividades realizadas no espaço interno: as fontes literárias mencionam o Odeion sendo usado como espaço para disputas musicais durante os festivais cívicos, palco de disputas filosóficas, tribunal, centro para a distribuição de grãos, sede de gabinetes de magistrados agonísticos e eventualmente abrigo para a cavalaria ateniense (Tofi, 2010). M. Miller também sugere um uso do Odeion associado às contribuições dos aliados atenienses durante o século $\mathrm{V}$ a.C.,

\footnotetext{
${ }^{2}$ Junto do odeion de Herodes Ático, na encosta sudoeste da acrópole, e o odeion de Agrippa, no centrosul da ágora ateniense.

${ }^{3}$ Fontes literárias: Aristófanes (Vespas, 1109), Andócides (Sobre os mistérios, 1.38), Hiperides (fr. 118), Xenofonte (Helênicas, 2.4.9), Demóstenes (Contra Neaera, 50.52; Contra Fórmio, 34.37), Cratino (fr. 73), Eupolis (fr. 325), Teofrasto (Caráteres 3.3), Heráclides Crítico (GGM 1.98), Diodoro Sículo (Biblioteca, 1.48.5-6), Vitrúvio (5.9.1), Apiano (Guerras Mitridáticas, 38), Plutarco (2.605a; 605a; Péricles, 13.9-11), Pausânias (1.20.4), Diógenes Laércio (7.184), Suida (s.v. Odeion), e os escólios de Ésquines (3.66-67) e Aristófanes (Vespas, 1109a). Inscrições: IG II ${ }^{2}$ 968.47; 1688.3; 3426; 3427.

${ }^{4}$ Conduzidas pela Sociedade Arqueológica Grega entre 1914-1929, conduzidas por P. Kastriotis, entre 1931-1932, conduzidas por A. Orlandos, além de demolições de residências acompanhadas por pequenas escavações nos anos 1960 e 1980 (Tofi, 2010:161-163). Cf. discussão exaustiva em Miller (1997:218-242).
} 
coletados e exibidos no teatro de Dioniso: o Odeion seria uma parada para a organização da procissão de contribuintes para o teatro (Miller, 1997: 241-242).

De acordo com as fontes literárias, a construção deve ser associada a Péricles, embora Vitrúvio mencione Temístocles como o responsável; estudiosos tradicionalmente tomam esta referência como um erro, ainda que não seja prudente descartar uma atividade construtiva inacabada antes dos trabalhos associados a Péricles (Mosconi, 2000; Tofi, 2010: 162). A conexão com Temístocles pode também ser explicada pelo programa ornamental do Odeion: Vitrúvio menciona o uso de espólios navais persas obtidos após a batalha de Salamina (Vitrúvio, 5.9.1), e Plutarco e Pausanias afirmam que sua cobertura de madeira era similar à tenda de Xerxes (Plutarco, Péricles, 13.9; Pausânias, 1.20.4). M. Miller, após discutir os problemas relacionados ao longo período de tempo entre a data da construção e as primeiras referências literárias à identificação com a tenda de Xerxes, conclui que a existência de uma sala hipostila, uma forma arquitetural originada no Irã séculos antes, era suficiente para a identificação por um grego das marcas persas do edifício (fig. 3; Miller, 1997: 239). Neste sentido, o Odeion de Péricles, além de suas funções práticas, poderia ser interpretado tanto como um memorial das Guerras Médicas quanto, considerando sua associação às contribuições dos aliados e a origem naval dos espólios, um símbolo do poder imperial ateniense.

O edifício não sofreu alterações significativas pelos três séculos seguintes, ainda que o programa de monumentalização da encosta sul da acrópole levado a cabo por Licurgo, no século IV a.C., possivelmente incluiu trabalhos de restauração no Odeion (Mercuri, 2004; Étienne, 2004: 122-126). A grande ruptura na história do edifício ocorreria somente em 86 a.C., quando ele foi total ou parcialmente destruído durante o saque de Atenas liderado pelo general romano L. Cornélio Sula ${ }^{5}$. O saque de 86 a.C. foi o ato final da trama iniciada dois anos antes, quando a secular aliança entre Atenas e Roma foi quebrada. O início das hostilidades entre Mitrídates VI Eupator, rei do Ponto, e Roma, em 89 a.C. - por conta, essencialmente, de disputas territoriais entre o Ponto e os reinos vizinhos da Bitínia e da Capadócia, protegidos por Roma (Madsen, 2009) -, fortaleceu os grupos anti-romanos atenienses. Em 88/7 a.C., um filósofo ateniense de nome Athenion, na qualidade de embaixador do rei pôntico, foi entusiasticamente recebido por membros das elites locais e pela companhia dos atores dionisíacos; foi eleito general dos hoplitas ${ }^{6}$ pelos cidadãos, num claro gesto de aliança com o inimigo de Roma. Pouco tempo depois, Athenion é substituído por outro filósofo ateniense,

\footnotetext{
${ }^{5}$ Evidências e problemas principais discutidos em Habicht (1997: 295-314), Hoff (1997), AntelaBernárdez (2009) e Morales (2015: 197-224).

${ }^{6}$ Sobre o cargo de general dos hoplitas, uma das principais magistraturas da democracia ateniense helenística, cf. Geagan (1967).
} 
chamado Aristion, o qual, com base em riquezas extraídas da ilha de Delos (então possessão ateniense, concedida por Roma em 166), teria instituído uma tirania prómitridática na cidade. Neste contexto, Sula, após violentos embates com Mário e seus seguidores pelo comando da guerra na Ásia (Santangelo, 2007: 1-32), parte de Roma para Atenas, onde inicia o cerco que, em alguns meses, levaria a cidade à capitulação. O massacre da população e as destruições de edifícios públicos deixaram profundas marcas na tradição literária e no registro arqueológico ateniense: Pausânias, escrevendo no século II d.C., qualifica as atitudes de Sula como "tão selvagens

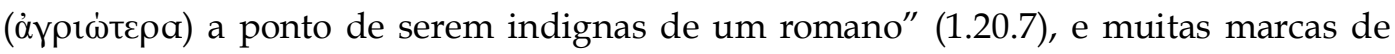
destruição datadas do período do saque puderam ser observadas nas escavações do século XX (Hoff, 1997). Um dos edifícios danificados foi Odeion de Péricles, ainda que as fontes literárias não estejam de acordo quanto ao responsável pela destruição: enquanto Apiano (Guerras Mitridáticas, 38) acusa Aristion e seus aliados que se refugiaram na acrópole de terem incendiado o edifício (de modo que o exército de Sula não tivesse materiais para a construção de máquinas de guerra), Pausânias (1.20.4), pelo contrário, acusa o próprio Sula de ter incendiado o edifício durante o cerco a Aristion e seus aliados na acrópole. Tal divergência pode ser derivada tanto de versões contraditórias produzidas em relação a diferentes pontos de vista quanto pelos diferentes projetos político-literários dos autores (Bucher, 2000; Alcock, 2001), como será discutido abaixo.

A história subsequente do Odeion é conhecida a partir de Vitrúvio e de duas inscrições encontradas na região do teatro de Dioniso. Vitrúvio afirma que "o rei Ariobarzanes restaurou (restituit)" o edifício "incendiado na guerra mitridática" (5.9.1), o que é corroborado por inscrições em duas bases de estátuas de Ariobarzanes da Capadócia encontradas próximo ao santuário de Dioniso, onde se lê:

Ao rei Ariobarzanes Filopator, filho do rei / Ariobarzanes Filoromano e da rainha / Atenais Filostorgos, tendo sido designados / por ele para a preparação do odeion, / Caio e Marcos Stalli filhos de Caio e / Melanipo, [dedicam] ao seu evergeta7 euergetes (IG II2 3426).

O povo [dedica] / ao rei Ariobarzanes / Filopator, filho do / rei Ariobarzanes / Filoromano e a rainha / Atenais Filostorgos / seu evergetas euergetes (IG II2 3426).

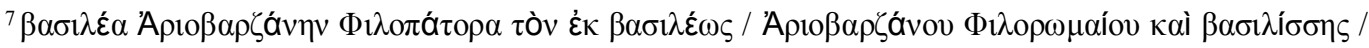

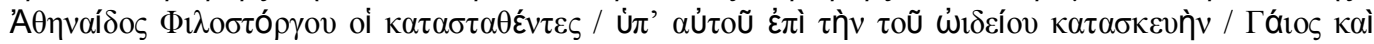
Mã

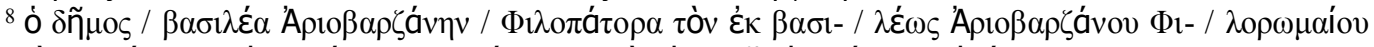

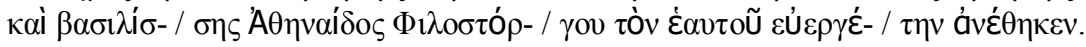


O homenageado é certamente Ariobarzanes II, rei da Capadócia entre 63/2 e 51 a.C., cujo reinado é a única indicação de datação para os trabalhos de restauração. A Capadócia, antiga satrapia persa, tornou-se reino independente em meados do século III a.C. com Ariarates III, fundador da dinastia ariarátida - de origem iraniana - que governaria a Capadócia até a morte de Ariarates IX em 96/5 a.C. (Will, 2003: 292). As relações do reino capadócio com Atenas são conhecidas a partir do século II: Stratonice, filha de Ariarathes IV e esposa primeiro de Eumenes II e depois de Átalo II de Pérgamo, recebeu uma estátua em Delos dedicada pelo demos ateniense (ID 1575); seu irmão Ariarathes V da Capadócia, que reinou entre 163 e 130, foi agonoteta de uma Grande Panatenéia e foi homenageado, junto da rainha Nysa (filha do rei Farnaces do Ponto), por um decreto honorífico da companhia dos artistas dionisíacos de Atenas (IG II2 1330) que determinava proclamações nos festivais e um dia de festa dedicado ao rei, associado a Dioniso; o decreto foi editado em agradecimento às garantias de segurança e proteção dadas pelo rei aos artistas em território capadócio (Habicht, 1997: 282). A última referência a um rei da dinastia ariarátida no âmbito do domínio ateniense é a dedicação de um busto a Ariarathes VII no santuário dos Cabeiri em Delos, ele próprio dedicado aos deuses, a Mitrídates VI e a Roma, no final do século II a. C. (ID 1562; Habicht, 1997: 263).

Um momento crucial - não apenas para a Capadócia, mas para toda a Ásia Menor - foi o fim da dinastia ariarátida em 96/5 a.C., com a deposição de Ariarathes IX, filho de Mitrídates VI, pelo Senado romano e por setores da elite capadócia. Nesta ocasião, após a rejeição das formas republicanas sugeridas pelo Senado aos capadócios (Justino, 38.2.8), um membro desta elite foi escolhido para assumir o trono, assumindo o nome de Ariobarzanes I Filoromano (96/5-63 BC). O reinado de Ariobarzanes I seria marcado por uma série de deposições (Sullivan, 1980: 1127-1137). A primeira deposição ocorreu em 95, realizada por Górdio, um aliado de Mitrídates VI; no mesmo ano, Ariobarzanes foi reconduzido ao trono por Sula, em sua primeira expedição no Oriente e então como governador da Cilícia, onde ficaria por cerca de três anos (Santangelo, 2007: 29-31). Plutarco (Sula, 5.4) relata o encontro de Sula, Ariobarzanes e Orobazos, um embaixador do rei Mitrídates II da Pártia - o que teria sido o primeiro encontro entre romanos e partas (Plutarco, Sula, 5.4; Santangelo, 2007: 28, n.39). Uma segunda deposição de Ariobarzanes I ocorreu por volta de 92, quando Tigranes I da Armênia antigo protetorado da Partia - o tira do poder e reestabelece no trono Ariarathes IX, filho de Mitrídates VI, que alegava legitimidade por um suposto parentesco com a dinastia ariarátida. O Senado de Roma intervém desta vez, em 90, com uma embaixada liderada por Manius Aquilius, que não apenas restaura o trono de Ariobarzanes, como também incita este último e o rei Nicomedes da Bitínia a atacarem o reino do Ponto, impedido de se defender por ordem do Senado - o que será o catalisador para a primeira guerra mitridática (Madsen, 2009). Ariobarzanes seria deposto uma terceira vez pelo próprio Mitrídates VI, por volta de 89/88, e será restabelecido pela segunda 
vez por Sula, em 85, após suas vitórias sobre o exército pôntico. Finalmente, Ariobarzanes será deposto por Mitrídates VI em 67, na passagem do comando romano da terceira guerra mitridática de Lucullus para Pompeu; em 63, seu trono será restaurado por Pompeu, mas em pouco tempo abdicaria em favor de seu filho, Ariobarzanes II Filopator (63-52), na presença do próprio Pompeu (Valério Máximo, Fatos e Ditos memoráveis, 7.7; Sullivan, 1980; Kallet-Marx, 1996, pp. 291-334).

O conturbado reinado de Ariobarzanes I Filoromano da Capadócia esteve intimamente vinculado à rearticulação das forças geopolíticas na Ásia Menor no final do século II a.C. (Habicht, 1989). O fim da dinastia atálida em Pérgamo e a longa decadência do poder selêucida abriria espaço para o crescimento das ambições dos reinos do Ponto, da Bitínia, da Armênia e dos impérios romano e parta na Ásia Menor e Anatólia. Aos reinos mais fracos - como era o caso da Paflagônia, de Sofene, de Comagene e, evidentemente, da Capadócia - restava o tênue equilíbrio da diplomacia com vizinhos ambiciosos e a poderosa mas distante autoridade romana, além das instabilidades criadas por facções internas associadas a diferentes opções geopolíticas e lealdades dinásticas.

Na Capadócia, Ariobarzanes I procurava conciliar as diferentes facções a partir de recursos híbridos de legitimação: o rei casou seu filho com uma das filhas de Mithridates VI do Ponto, manteve tradições iconográficas ariarátidas (Simonetta, 1961), bem como reforçou os laços com Roma e, acima de tudo, com Sula e Pompeu (Apiano, Guerras Mitridáticas., 61; Dio, 36.9.2; Sullivan, 1980, p. 1130-2; Santangelo, 2007: 50-66). Após assumir o trono em 63 a.C., Ariobarzanes II continua a política conciliatória do pai: enquanto sua coroação ocorreu sob os auspícios de Pompeu em pessoa, sua rainha, filha de Mithridates VI, assumiu o mesmo nome de sua sogra, Athenais Philostorgos, sinalizando a união entre a nova dinastia e as facções pró-pônticas; o próprio epiteto adotado pelo novo rei, Filopator, indicava a continuidade em relação ao reinado de seu pai (Sullivan, 1980: 1137-1138). A estratégia conciliatória, entretanto, não obteve sucesso duradouro: após precisar do apoio romano para reprimir uma revolta em 57 a.C., o rei foi assassinado em 52 a.C. por uma conspiração possivelmente associada à longa oposição anti-ariobarzânida (Sullivan, 1980: 1139). A conspiração pode ter sido impulsionada pelas crescentes ambições do reino parta na Ásia Menor: Cícero, em uma carta de 51 a.C., menciona rumores sobre uma invasão parta na Cilícia através do território capadócio, que estava, de acordo com o autor, "aberta aos invasores" (ad Familiares, 15.2). Se Cícero estava certo, seria plausível a existência de uma facção própártica na Capadócia, especialmente após a vitória parta sobre o exército romano liderado por Crasso em 53 a.C.

Neste ponto, podemos voltar à questão da restauração do Odeion. Por que um rei capadócio, com tantos desafios em seu próprio reino, estaria interessado na restauração de um monumento histórico ateniense? A questão pode ser respondida, por um lado, 
através das conexões entre Ariobarzanes II, Atenas, Sula e Pompeu. O rei é listado como efebo em um decreto ateniense no ano de 80/79 a.C., segundo o qual os efebos daquele ano ofereceram sacrifícios durante a Sylleia, festival celebrado desde 84/3 a.C. em honra de Sula (IG II2 1039.57). Ou seja: um rei capadócio, cujo pai foi reentronado diversas vezes por Sula e que como efebo sacrificou em honra de Sula em Atenas, restaurou um edifício destruído, justamente, durante o saque de Sula em 86 a.C. Esta associação pode estar na base do desacordo acerca do responsável pela destruição: enquanto Apiano, escrevendo na Alexandria do século I d.C. contra grupos antiromanos, culpa explicitamente o "tirano" Aristion pela destruição, Pausânias, escrevendo para uma audiência filelênica, enfatiza a barbárie de Sula, destruidor do Odeion. Culpar Sula pela destruição, em certos contextos tais como a Atenas do século I a.C. ou a Alexandria do século I d.C., poderia ser tomado como uma postura antiromana; este não era o caso, entretanto, na Periegesis de Pausânias, dado o celebrado modelo filelênico oferecido pelo imperador Adriano. As honras dadas pelos atenienses para Sula logo após seu retorno à cidade em 84 a.C. (Kallet-Marx, 1996: 212-221) poderiam ter sido parte de uma operação que visava justificar a violência romana por meio da associação de Aristion com a tirania/barbárie e de Sula com a restauração da antiga politeiai: de fato, a cunhagem de $84 / 3$ a. C. figurou no reverso os tardo-arcaicos tiranicidas Harmodios e Aristogeiton (Habicht, 1976), no mesmo ano em que o venerável festival em honra de Teseu (a Theseia), herói civilizador local visto como um dos pais da democracia (Walker, 1995), foi renomeado em honra de Sula (Raubitschek, 1951). Este pode ter sido o contexto para a culpabilização de Aristion, o "tirano" aliado ao "bárbaro" Mitrídates, pela destruição do Odeion de Péricles, um memorial da democracia e da oposição à barbárie. A participação de Ariobarzanes II na restauração, empregando dois arquitetos romanos, pode ser interpretada como parte desta dissociação entre Roma e as destruições, uma operação facilitada seja pelas benfeitorias dadas pelo fileleno romano Tito Pompônio Atticus à cidade durante as duas décadas posteriores ao saque (Morales, 2015: 225-235), seja pelo presente de 50 talentos dado por Pompeu para restaurações em Atenas em 62 a.C., após sua vitória decisiva sobre Mitrídates e a coroação de Ariobarzanes como rei da Capadócia (Valverde, 2005; Morales, 2015: 235-248). Com efeito, a restauração do Odeion não deve estar ligada com os 50 talentos oferecidos por Pompeu, dada a ausência de seu nome (ou de marcas de apagamento) nas inscrições relacionadas à restauração mencionadas acima; não obstante, o clima de mudança na imagem dos romanos de saqueadores para evergetas e salvadores (Habicht, 1997: 332) oferecia a perfeita oportunidade para a restauração do edifício, desse modo reforçando os laços entre o antigo efebo ateniense Ariobarzanes II com o poder romano e a tradição clássica ateniense.

Por outro lado, a escolha da restauração do Odeion pode ser explicada tanto pela audiência mediterrânica alcançada por Atenas quanto pelo intenso significado antibárbaro implícito do programa estrutural e ornamental do edifício. De fato, por 
meio desta operação Ariobarzanes poderia reforçar a associação entre Mitrídates e os partas com os persas aquemênidas (Ballesteros-Pastor, 2005; Rose, 2005; Curtis, 2007), posicionando a si mesmo na longa comemoração mítico-histórica anti-bárbara. A localização do Odeion, logo abaixo da fachada oriental do Pártenon e da dedicação atálida localizada próxima ao seguimento sudeste dos muros da acrópole monumentos que comemoravam a sequência de vitórias sobre os gigantes, os centauros, as amazonas, os troianos, os persas e os gauleses - facilitava a associação de Ariobarzanes e de Roma com esta cosmológica disputa da civilização contra a barbárie (Morales, 2015: 102-123). Assim, a participação de Ariobarzanes II pode ser interpretada como uma estratégia de legitimação, direcionada para uma audiência filelênica mediterrânica, de sua posição pró-romana contra os dissidentes capadócios e inimigos estrangeiros (Ponto, Armênia, Pártia) supostamente "pró-bárbaros".

Do ponto de vista da história urbana ateniense, por sua vez, a restauração tem uma natureza ambígua. Por um lado, continuava a secular tradição do evergetismo construtivo de reis helenísticos na cidade, fortemente influenciada pelo discurso antibárbaro presente na paisagem urbana ateniense (Morales, 2015: 346-356). Além disso, não somente pelo uso do edifício para as competições musicais das Grandes Panatenéias, mas também por sua proximidade com o santuário de Dioniso - cuja guilda, como dito acima, tinha desde o século II a. C. garantias reais de segurança e imunidade no território capadócio -, Ariobarzanes continuava o padrão do evergetismo monárquico do século II a. C. com construções relacionadas, por proximidade e/ou uso, à tradição agonística ateniense, inscrevendo seu nome nesta particularmente visível dimensão da história evergética da cidade.

Entretanto, a restauração do Odeion deve ser distinguida do evergetismo construtivo do século II a. C. em um aspecto bastante importante: enquanto os monarcas atálidas construíam edifícios inteiramente novos, claramente inspirados pelas tradições arquiteturais pergamenas (que alteravam profundamente a paisagem urbana, tais como as stoai na ágora e na encosta sul da acrópole), o rei capadócio restaurou um antigo edifício sem quaisquer inovações ou alterações na planta original. Embora a escolha de Vitrúvio pela palavra restituto possa também significar "inovar", as escavações revelaram que o principal problema funcional do edifício - os obstáculos à visibilidade criados pelas colunas internas - não foi resolvido, a despeito dos impressionantes desenvolvimentos técnicos contemporâneos relacionados à cobertura de grandes áreas sem a necessidade de dezenas de suportes internos, aplicados, por exemplo, no Bouleuterion de Mileto e no Odeion de Pompéia (Winter, 2006: 96-111, 135-149). Ademais, a decisão de restaurar um edifício profundamente relacionado à memória clássica revela, em um sentido mais amplo, uma atitude antiquária em relação ao espaço urbano. O desejo de resgatar o passado tal qual ele era - de acordo com tradições escritas e orais - era subjacente a este "urbanismo antiquário", 
radicalmente diferente do programa urbano das intervenções atálidas em Atenas, mais preocupadas em atualizar a cidade em função de padrões helenísticos do que restaurar edifícios relacionados ao passado clássico (Morales, 2015: 353-357).

O saque de Sula à cidade, com sua quase realizada possibilidade de total aniquilação, estava na base desta atitude: os suportes materiais da herança cultural ateniense deveriam ser protegidos e restaurados. O saque criou uma nova relação de atenienses e estrangeiros com o espaço urbano. Os esforços de Cícero em defesa da casa de Epicuro e seu não realizado projeto de doação de um novo pórtico para a Academia em meados do século I a. C. (Rawson, 1985; Morales, 2015: 228-232) e, acima tudo, o amplo programa augustano de restaurações de edifícios no final do século I a. C. (Schmalz, 1994: 43-68; Morales, 2015: 259-344) são evidências da difusão desta atitude antiquária em relação à produção do espaço. Que o primeiro passo tenha sido dado por um rei com origens persas governando um reino oriental demonstra, eloquentemente, como a história ateniense não pode ser isolada das redes e dos processos de integração mediterrânicos, com seus historicamente construídos "bárbaros" - romanos ou pôntios, capadócios ou partas, velhos ou novos persas - simultaneamente incluídos na e excluídos da paisagem urbana ateniense. 


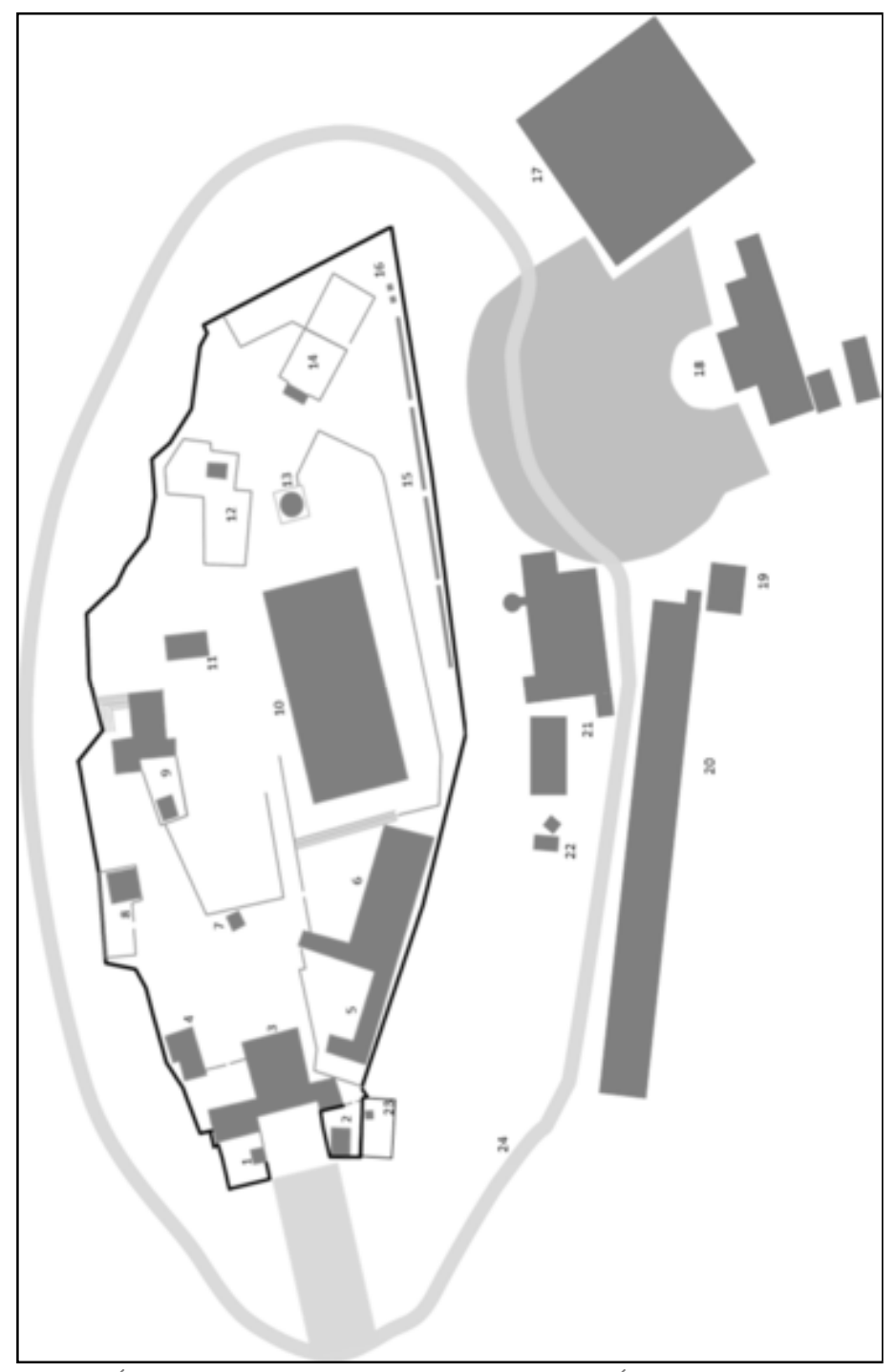

FIG 1. PLANTA DA ACRÓPOLE ATENIENSE NO FINAL DO SÉCULO I A. C. 1. MONUMENTO DE AGRIPA. 2. SANTUÁRIO DE ATHENA NIKE. 3. PROPILEU. 4. 'EDIFÍCIO NOROESTE'. 5. SANTUÁRIO DE ÁRTEMIS BRAURÔNIA. 6. CALCOTECA. 7. ESTÁTUA DE ATENA PROMACHOS. 8. CASA DAS ARREPHOROI. 9. ERECHTHEION. 10. PARTENON. 11. ALTA DE ATENA POLIAS. 12. SANTUÁRIO DE ZEUS POLIEUS. 13. MONOPTEROS DE ROMA E AUGUSTO. 14. SANTUÁRIO DE PANDION. 15. DEDICAÇÃO ATÁLIDA. 16. COLOSSOS ATÁLIDAS (?). 17. ODEION DE PÉRICLES. 18. SANTUÁRIO DE DIONISO. 19. MONUMENTO DE NÍCIAS. 20. STOA DE EUMENES. 21. ASKLEPIEION. 22. SANTUÁRIO DE ÍSIS E TÊMIS. 23. SANTUÁRIO DE APHRODITE PANDEMOS. 24. PERIPATOS. 


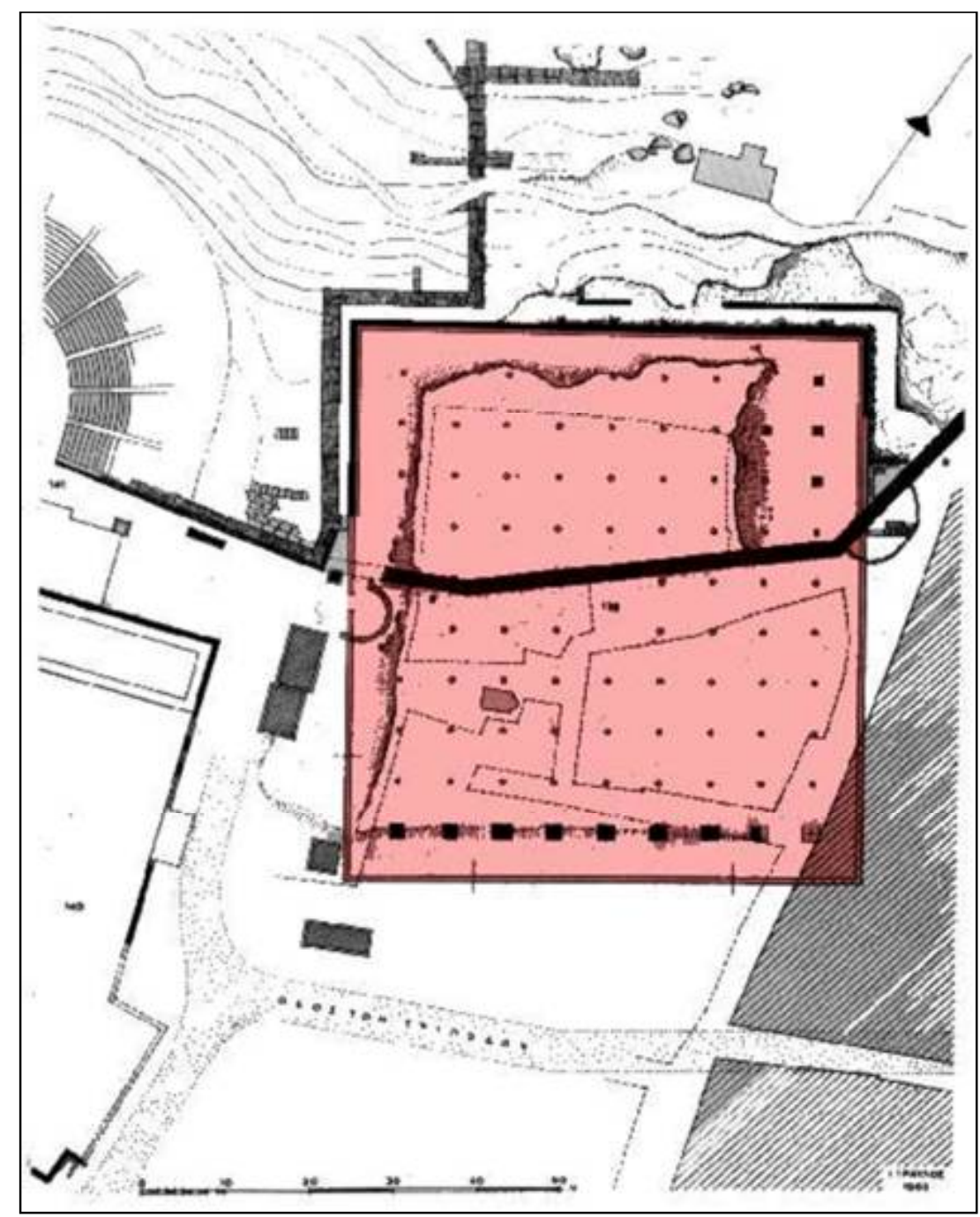

FIG 2. PLANTA DO ODEION DE PERIKLES (DESTACADO EM VERMELHO) DE ACORDO COM J. TRAVLOS (1980: 398, FIG. 502). 


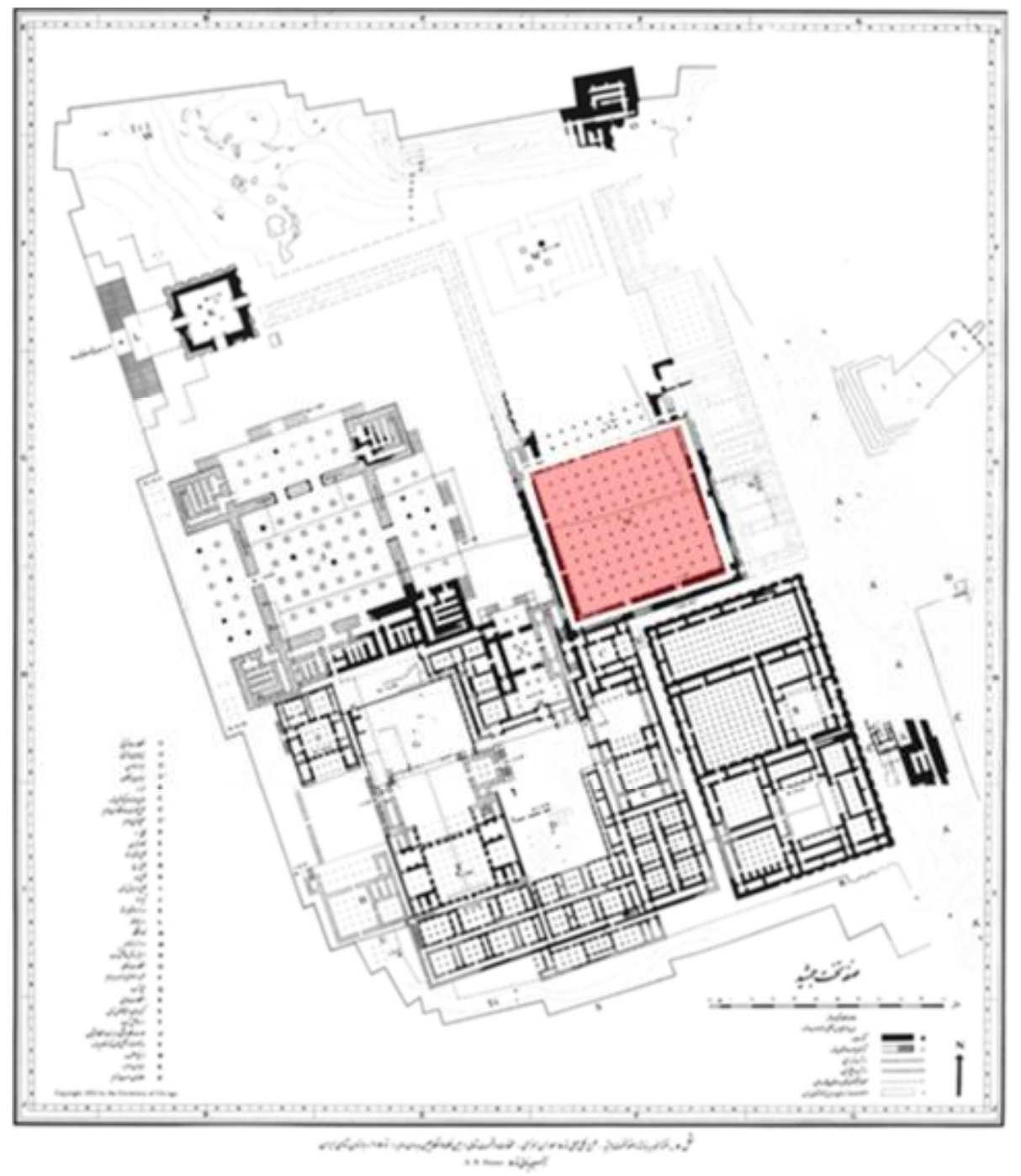

FIG 3. PLANTA DE PERSÉPOLIS NO SÉCULO V A.C. SALA DAS CEM COLUNAS DESTACADA EM VERMELHO (IRANICA ONLINE9).

\section{Referências Bibliográficas}

ALCOCK, S.; CHERRY, J.; ELSNER, J. (eds). Pausanias: Travel and Memory in Roman Greece. Oxford: Oxford University Press, 2001.

9 Disponível no site: http://www.iranicaonline.org/uploads/files/Persepolis/persepolis fig 2.jpg . Consultado em dezembro de 2015. 
ANTELA-BERNARDEZ, B. Sila no vino a aprender Historia Antigua. El asedio de Atenas en 87/6 A.C. REA, v. 111, n. 2, p. 475-491, 2009.

BALLESTEROS-PASTOR, L. The Pontic Identity: Hellenism, Civic Life and Mithridates' Propaganda. Paper delivered at the University of Aarhus (Denmark) at 10 March 2005. Available at the site: http://www.pontos.dk/publications/paperspresented-orally/oral-files/Bal_pontic.pdf .

BRUNEAU, Ph. Quatre propos sur l'archéologie nouvelle. Bulletin de correspondance hellénique, v. 100, n. 100-1, pp. 103-135, 1976.

BUCHER, G. The Origins, Program, and Composition of Appian's Roman History. Transactions of the American Philological Association, v. 130, pp. 411-458, 2000.

BURSTEIN, S. Greek identity in the Hellenistic Period. In: ZACHARIA, K. (ed). Hellenisms: Culture, Identity, and Ethnicity from Antiquity to Modernity. Hampshire: Ashgate, 2008, pp. 79-78.

CHAMPION, C. Cultural politics in Polybius' Histories. Berkeley: University of California Press, 2004.

CURTIS, V. The Iranian Revival in the Parthian Period. In: CURTIS, V.; STEWART, S. The Idea of Iran II: the Age of the Parthians. London: Tauris, 2007, pp. 1-25.

ECKSTEIN, A. Mediterranean Anarchy, Interstate War, and the Rise of Rome. Berkeley: University of California Press, 2006b.

. From Anarchy to Hierarchy in the Hellenistic Mediterranean, 230-170 BC. Oxford: Blackwell, 2008.

ÉTIENNE, R. Athènes: espaces urbains et histoire. Paris: Hachette, 2005.

GAUTHIER, Ph. La cité grecque et leurs bienfaiteurs. Paris, BCH (supp. 12), 1985.

GEAGAN, D. The Athenian Constitution after Sulla (Hesperia Supplement 12). Princeton: American School of Classical Studies at Athens, 1967.

GOPNIK, H. Why Columned Halls? In: CURTIS, J.; SIMPSON, J. (eds). The World of Achaemenid Persia. London: British Museum Press, 2010, pp. 195-207.

GRUEN, E. Greeks and non-Greeks. In: BUGH, G. (ed). The Cambridge Companion to the Hellenistic world. Cambridge: Cambridge University Press, 2006, pp. 295-324.

GUARINELLO, N. Uma morfologia da História: as formas da História Antiga. Politeia, v. 3, n. 1, pp. 41-61, 2003.

Revista Heródoto. Unifesp. Guarulhos. v. 01, n. 01. Março, 2016. p. 55-72. 
. Ordem, integração e fronteiras no Império Romano. Um ensaio. Mare Nostrum, v. 1, pp. 113-127, 2010.

HABICHT, C. Zur Geschichte Athens in der Zeit Mithridates' VI. Chiron, n. 6, 1976, pp. 127-142.

. The Seleucids and their rivals. In: ASTIN, A.; WALBANK, F.; FREDERIKSEN, M.; OGILVIE, R. (eds). The Cambridge Ancient History (2nd. edition), vol. VIII: Rome and the Mediterranean to 133 B.C. Cambridge: Cambridge University Press, 1989, pp. 324387.

Athens from Alexander to Antony. Translated by Deborah Lucas Schneider. Cambridge: Harvard University Press, 1997.

HALL, E. Inventing the Barbarian. Oxford: Oxford University Press, 1989.

HALL, J. Hellenicity: between Ethnicity and Culture. Chicago and London: University of Chicago Press (2002).

HERZFELD, E. Iran and the Ancient East. Oxford: Oxford University Press, 1941.

HOFF, M. Laceteratae Athenae: Sulla's siege of Athens in 87/6 B. C. and its aftermath. In: HOFF, M. C.; ROTROFF, S. (eds.). The Romanization of Athens. Oxford, Oxford University Press, 1997, pp. 33-51.

Greece and the Roman Republic: Athens and Corinth from the Late Third Century to the Augustan Era. In: EVANS, J. (ed). A Companion to the Archaeology of the Roman Republic. Oxford: Blackwell, 2013, pp. 559-578.

HORDEN, P.; PURCELL, N. The Corrupting Sea: a Study of Mediterranean History. Oxford: Blackwell, 2000.

KALLET-MARX, R. Hegemony to Empire. The Development of the Roman Imperium in the East from 148 to 62 B.C. Berkeley / Los Angeles / Oxford: University of California Press, 1996.

LANG, D. Iran, Armenia and Georgia. In: YARSHATER, E. The Cambridge History of Iran, vol. 3.1. Cambridge: Cambridge University Press, 2000, pp. 505-536.

MA, J. Statues and cities: Honorific Portraits and Civic Identity in the Hellenistic World. Oxford: Oxford University Press, 2013.

MADSEN, J. The Ambitions of Mithridates VI : Hellenistic Kingship and Modern Interpretations. In: HOJTE, J. (ed). Mithridates VI and the Pontic kingdom. Aarhus: Aarhus University Press, 2009, pp. 191-201. 
MILLER, M. Athens and Persians in the Fifth Century BC: A Study in Cultural Receptivity. Cambridge: Cambridge University Press, 1997.

MORALES, F. Atenas e o Mediterrâneo romano: espaço, evergetismo e integração (200 a.C. 14 d.C.). Tese. Universidade de São Paulo, 2015.

MORRIS, I. Mediterranization. Mediterranean Historical Review, v 18, 30-55, 2003.

MOSCONI, G. La democrazia ateniese e la 'nuova' musica: l'Odeion di Pericle. CASSIO, A.; MUSTI, D.; ROSSI, L. (edd.). Synaulía: cultura musicale in Grecia e contatti mediterranei. Annali dell'Istituto Orientale di Napoli, Sezione filologico-letteraria, quaderni 5, pp. 217-316, 2000.

OLBRYCHT, M. Mithridates VI Eupator and Iran. In: HOJTE, J. (ed). Mithridates VI and the Pontic kingdom. Aarhus: Aarhus University Press, 2009, pp. 163-190.

RAUBITSCHEK, A. Sylleia. In: Coleman-Norton, P. (ed). Studies in Roman Economic and Social History in Honor of Allan Chester Johnson. Princeton: Princeton University Press, 1951, pp. 49-57.

ROSE, B. The Parthians in Augustan Rome. American Journal of Archaeology, v. 109, n. 1, pp. 21-75, 2005.

SANTANGELO, F. Sulla, the Elites and the Empire. A Study of Roman Policies in Italy and the Greek East. Leiden/Boston: Brill, 2007.

SKIBO, J.; SCHIFFER, M. People and Things. A Behavioral Approach to Material Culture. New York: Springer-Verlag, 2008.

SILVA, T. (org). Identidade e Diferença: a perspectiva dos Estudos Culturais. Trad. Tomaz Tadeu da Silva. 10. ed. Petrópolis, RJ: Vozes, 2011.

SIMONETTA, B. Notes on the Coinage of the Cappadocian kings. The Numismatic Chronicle and Journal of the Royal Numismatic Society (seventh series), v. 1, pp. 9-50, 1961.

SPAWFORTH, A. Greece and the Augustan Cultural Revolution. Cambridge: Cambridge University Press, 2012.

STEWART, A. Attalos, Athens and the Akropolis. The Pergamene "Little Barbarians" and their Roman and Renaissance Legacy. Cambridge: Cambridge University Press, 2004.

SULLIVAN, R. The Dinasty of Cappadocia. In : Aufstieg und Niedergang der römischen Welt, II.7.2. Berlin: 1980, pp. 1159-1161.

TRAVLOS, J. Pictorial dictionary of Ancient Athens. New York: Praeger, 1971. 
THIERRY, N. La Cappadoce de l'antiquité au Moyen Âge. Brepols : Turnhout, 2002.

TOFI, M. L'Odeion di Pericle. In: GRECO, E. (a.c.). Topografia di Atene : sviluppo urbano e monumenti dalle origini al III secolo d.C. Tomo 1. Atene / Paestum: Pandemos, 2010, pp. 161-163.

VEYNE, P. Le pain et le cirque: sociologie historique d'un pluralisme politique. Paris: Éditions du Seuil, 1976.

VALVERDE, L. Pompeyo Magno y Atenas. Polis, v. 17, pp.7-30, 2005.

VLASSOPOULOS, K. Greeks and Barbarians. Cambridge: Cambridge University Press, 2013.

WALKER, H.J. Theseus and Athens. Oxford: Oxford University Press, 1995.

WALLACE-HADRILL, A. Rome's Cultural Revolution. Cambridge: Cambridge University Press, 2008.

WILL, E. Histoire politique du monde hellénistique : 323-30 av. J.-C. 2 vols. Paris, Seuil, 2003. [1ª. ed.1966-1967, 2a . ed. 1979-1982].

WOLF, M. Appian, the Rise of Rome, and Monarchy: An Analysis of the Romaika through the Portrayal of Africanus and Aemilianus. Thesis. Williams College, Massachusetts, 2004.

WINTER, F. Studies in Hellenistic Architecture (Phoenix Supplementary Volumes). Toronto: University of Toronto, 2006. 